\title{
Commentary: The nature of aortic root disease, patients' prognoses, and Marcus Aurelius' Meditations
}

Amedeo Anselmi, MD, PhD, and Jean-Philippe Verhoye, MD, PhD

From the Division of Thoracic and Cardiovascular Surgery, Pontchaillou University Hospital, Rennes, France. Disclosures: Authors have nothing to disclose with regard to commercial support.

Received for publication Nov 14, 2018; accepted for publication Nov 14, 2018; available ahead of print Dec 29, 2018.

Address for reprints: Amedeo Anselmi, MD, PhD, Division of Thoracic and Cardiovascular Surgery, Pontchaillou University Hospital, Rennes, France (E-mail: amedeo.anselmi@chu-rennes.fr).

J Thorac Cardiovasc Surg 2019;158:992-3

$0022-5223 / \$ 36.00$

Copyright (c) 2018 by The American Association for Thoracic Surgery

https://doi.org/10.1016/j.jtcvs.2018.11.052

Since the 2000s, the standardization of techniques and appropriateness of indications have rendered increasingly predictable the results of aortic root replacement surgery (ARR), which was once associated with remarkable operative risk. In current practice, extending the repair beyond the aortic annulus in elective cases of aneurysm disease (in patients with preserved left ventricular ejection fraction [LVEF] and in experienced centers) is associated with a mortality rate $\left(0.7 \%{ }^{1}\right)$ that evokes state-of-the-art, lowrisk, primary isolated aortic valve replacement. One further, less hidden message of the current article by Langer and colleagues $^{1}$ consists in the prognostic impact on patients undergoing ARR of preoperatively depressed LVEF: early mortality increases to $5 \%$ in patients with preoperative LVEF between $50 \%$ and $40 \%$ and to $14 \%$ in patients with LVEF lower than $40 \%$.

Such effect in the ARR cohort seems to be greater than observed in patient subgroups undergoing isolated aortic valve surgery or coronary revascularization with similarly depressed LVEF. This message represents the justification of this research paper and constitutes the basis to discuss prediction of outcomes, patient counseling, and projection of health care costs (hospital stay and the rate of several postoperative complications are also well stratified by LVEF subgroups). A restricted cubic spline curve is also appropriately presented, with the intent to evaluate a nonlinear relationship between LVEF (as a continuous variable) and an outcome (death). The authors must be commended for these insights, for the first time in an exclusive ARR series.

One first comment recalls the need for preoperative multimodal evaluation of the more severe cases in the perspective of advanced heart failure therapies (left ventricular assist devices or heart transplantation) should myocardial failure occur postoperatively. Hence, cooperation within heart failure centers is required for the safer management of these patients and guarantee a second-line strategy.

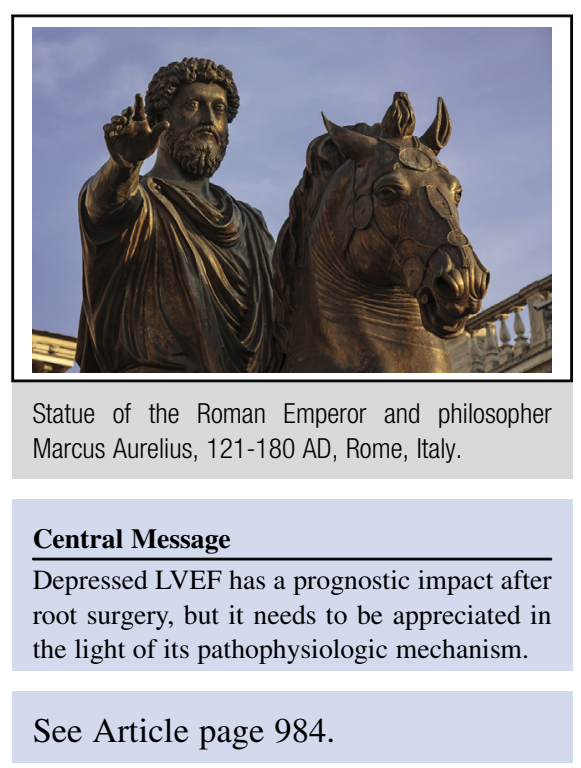

One second comment is the low number of patients included in the lower LVEF strata $(8.4 \%$ and $10 \%$ of the global population), evoking the authors' preoperative patient selection and refusal of an unknown number of cases presenting with depressed LVEF. In the interpretation of results, the possibility of selection bias in that sense should be considered.

As a third comment, information about the underlying pathophysiologic mechanisms leading to LV dysfunction is lacking from the present manuscript. In the great majority of patients receiving ARR for thoracic aortic aneurysm (and despite that mixed indications to surgery were encompassed herein, including infective endocarditis and acute dissection), depressed LVEF is likely related to aortic valve dysfunction in these patients. As a lesson learned from aortic valve surgery, the immediate postoperative behavior of a failing LV (as well as the chances of reverse remodeling in the long term) can be significantly different according to the modality of valve failure associated with depressed LVEF, in particular, predominant valve regurgitation (with chronic volume overload and dilated LV cavity) versus severe valve stenosis (where valve replacement yields immediate relief of pressure overload). Such information, beyond crude LVEF value and its interpretation on the basis of cubic spline analysis, must be considered for both a rational appreciation of prognosis and patient counseling and is lacking in the current paper. Other variables to be evaluated are the degree of LV dilatation, the thickness of the LV myocardium, and the residual transvalvular gradient. As 
indicated by Marcus Aurelius in his second-century Meditations, the first step in approaching a problem should rely on the appreciation of its nature: "This thing, what is it in itself, in its own constitution? What is its substance and material? And what its causal nature (or form)?",2

\section{References}

1. Langer NB, Ando M, Simpson M, van Boxtel BS, Sorabella RA, Patel V, et al Influence of left ventricular ejection fraction on morbidity and mortality after aortic root replacement. J Thorac Cardiovasc Surg. 2019;158:984-91.e1.

2. The Meditations of Marcus Aurelius Antoninus. Translated by George Long 1862 Book VIII, 11. Charleston, SC: Nabu Press; 2010. 